\title{
Electrified Soft Interface as a Selective Sensor for Cocaine Detection in Street Samples
}

\author{
Lukasz Poltorak, ${ }^{*}{ }^{\dagger}$ Irene Eggink, Marnix Hoitink, ${ }^{\dagger}$ Ernst J. R. Sudhölter, ${ }^{\dagger}$ and Marcel de Puit ${ }^{\dagger, \dagger}$ \\ ${ }^{\dagger}$ Delft University of Technology, Department of Chemical Engineering, Van der Maasweg 9, 2629 HZ Delft, The Netherlands \\ ${ }^{\ddagger}$ Netherlands Forensic Institute, Forensic Biometric Traces, Laan van Ypenburg 6, 2497 GB The Hague, The Netherlands
}

\section{Supporting Information}

\begin{abstract}
A straightforward, direct, and selective method is presented for electrochemical cocaine identification in street samples. The sensing mechanism is based on a simple ion transfer reaction across the polarized liquid-liquid interface. The interfacial behavior of a number of cutting agents is also reported. Interfacial miniaturization has led to improved electroanalytical properties of the liquid-liquid interface based sensor as compared with the macroscopic analogue. The reported method holds great potential to replace colorimetric tests with poor selectivity for on-site street sample analysis.
\end{abstract}

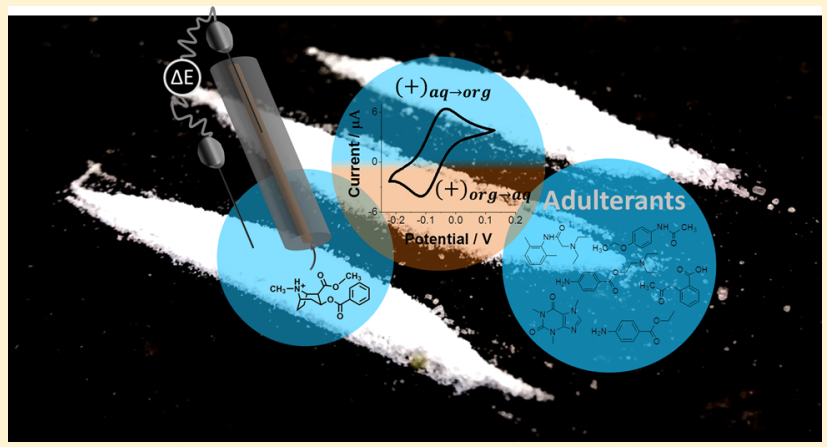

A fter cannabis, cocaine is one of the most used illicit drugs in Europe and the US. ${ }^{1,2}$ Around 17 million people worldwide are estimated to be cocaine users. ${ }^{3}$ As an addictive drug, it leads to a number of harmful direct (psychological and physiological disorders) and indirect (hepatitis C or/and HIV infections) effects. Increasing worldwide cocaine production ${ }^{3}$ together with elaborated trafficking techniques do not facilitate the work of responsible officers from police, custom borders, or forensic institutes. The need for portable, small, easy in operation, sensitive, and selective sensors able to measure a wide range of cocaine concentrations is therefore high. In other words, there is a gap between the primitive colorimetric tests (e.g., Scott test) ${ }^{4}$ and sophisticated techniques requiring costly instrumentation (e.g., chromatography and mass spectrometry). The vast amount of effort related to cocaine detection is based on different aptamer-based configurations. ${ }^{5}$ In general, the specific cocaine binding to an appropriately engineered aptamer chain leads to conformational changes that can be detected with fluorescence triggering ${ }^{6}$ or quenching, ${ }^{7,8}$ simple solution color change utilizing metallic nanoparticles, ${ }^{9,10}$ or dyes entrapped in the folded aptamer structure, ${ }^{11}$ change in the resonance frequency of the quartz crystal modified with the aptamer reach affinity layer, ${ }^{2,13}$ or drop in ionic currents flowing through the nanopore (membrane protein channel $\alpha$-hemolysin) embedded in the free-standing lipid bilayer. ${ }^{14,15}$ A lot of attention was devoted to electrochemical sensors modified with the cocaine-specific aptamer. Three main signal transduction mechanisms can be distinguished: (i) increasing charge transfer resistance after cocaine binding and aptamer folding, ${ }^{16-18}$ (ii) bringing the redox probe modified aptamer close to the electrode surface upon cocaine binding, ${ }^{19-21}$ or (iii) the redox-recycling mechanism where the redox mediator can shuttle electrons from the electrode surface to the appropriately modified aptamer. ${ }^{22,23}$ All these examples are rather complex, require multiple, mutually interacting components, and rely on aptamer selectivity. Direct electrochemical oxidation of cocaine tertiary amine functionality at carbonbased electrodes ${ }^{24,25}$ provides a simple option for cocaine detection. Recently, De Jong et al. reported a very elegant method for direct cocaine discrimination from street samples used on a glove printed carbon electrode. ${ }^{26}$

Electrochemistry at the liquid-liquid interface (also known as an interface between two immiscible electrolyte solutions ITIES) allows for the unconventional detection of analytes where the signal originates from interfacial ion transfer reaction rather than oxidation/reduction. ${ }^{27}$ The selectivity of the bare (unmodified) liquid-liquid interface is purely governed by ionic partitioning. ${ }^{28-30}$ Additional selectivity can be induced via incorporation of ionophores ${ }^{31,32}$ into one of the immiscible phases or interfacial decoration with a charge or size selective membrane. ${ }^{33,34}$ Illicit drug sensing at the ITIES is limited to a recent report concerning gamma-aminobutyric acid detection at the nanopipette-ITIES ${ }^{35}$ and pharmacokinetic studies devoted to a few opioids and amphetamine-like drugs. ${ }^{36}$ Alternative detection of cocaine at a soft junction was reported by Wägli et al., where its paritioning from the aqueous phase to the tetrachloroethylene droplets formed in the microfludic devices was continuously monitored by IR spectrsocopy. ${ }^{37}$

Adulterants or cutting agents added purposely to cocaine powders aim only to increase profits by lowering the amount of cocaine in the samples or to mislead authorities when these are

Received: February 27, 2018

Accepted: May 21, 2018

Published: May 21, 2018 

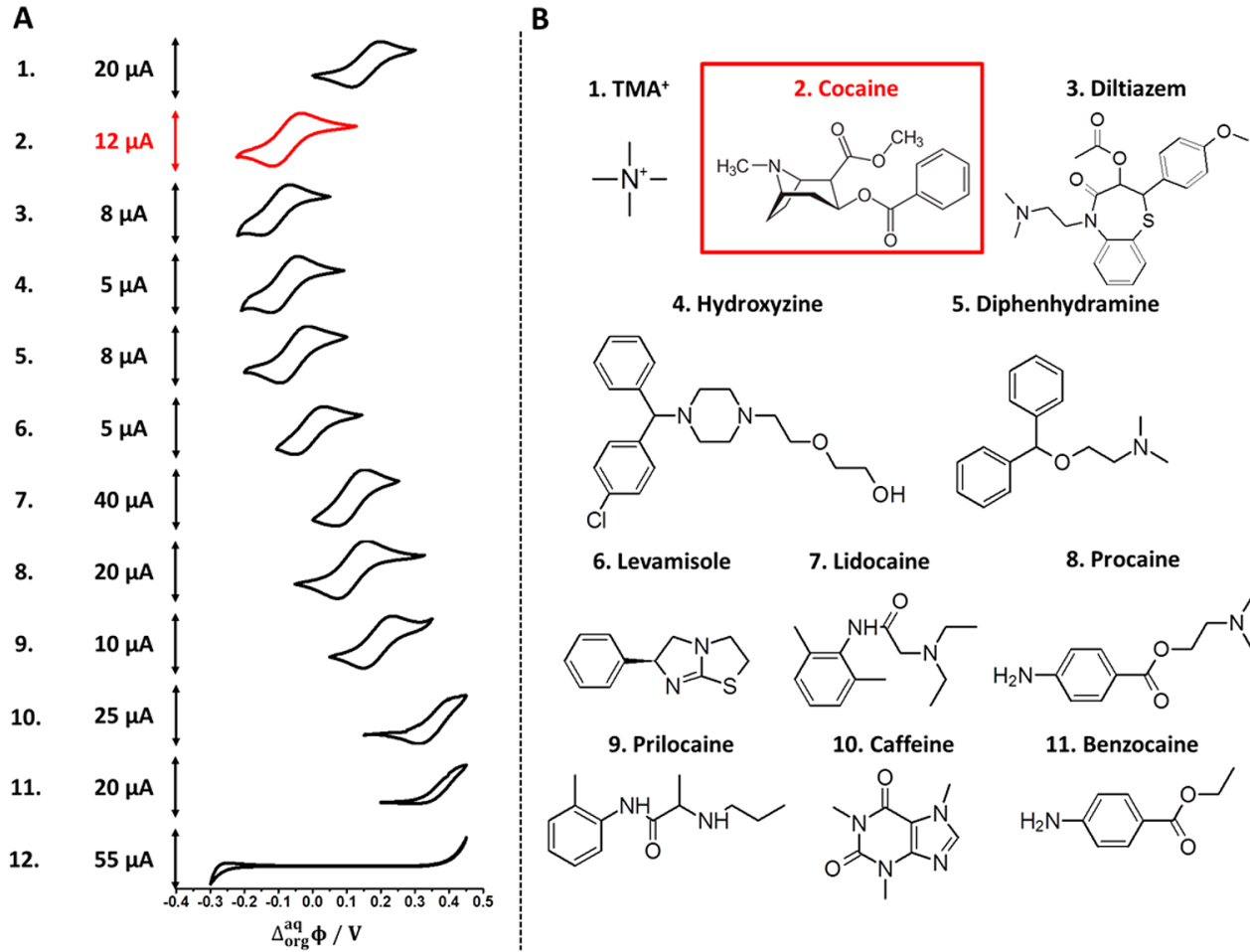

4. Hydroxyzine

5. Diphenhydramine
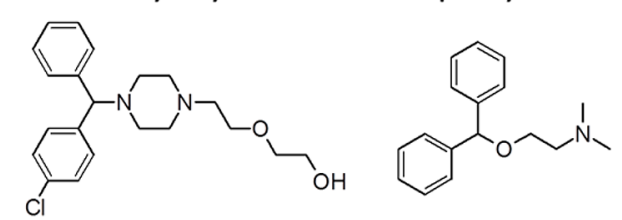

6. Levamisole
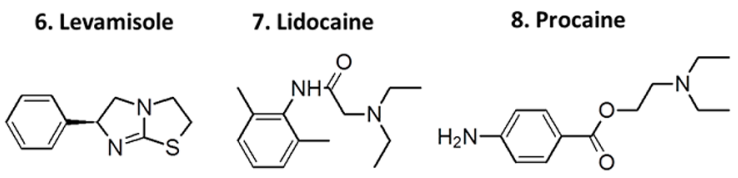

10. Caffeine

11. Benzocaine

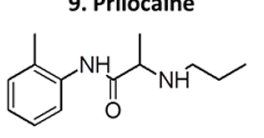<smiles>Cn1c(=O)c2c(ncn2C)n(C)c1=O</smiles>

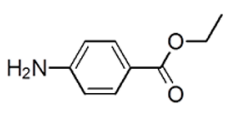

Figure 1. (A) Ion transfer voltammograms of cocaine (in red) and frequently used cutting agents (in black). (B) Chemical structure of cutting agents. Number related to voltammograms; cocaine and cutting agents correspond to (1) $90.4 \mu \mathrm{M} \mathrm{TMA}^{+}$, (2) $100.7 \mu \mathrm{M}$ cocaine, (3) $52.6 \mu \mathrm{M}$ diltiazem, (4) $85.5 \mu \mathrm{M}$ hydroxyzine, (5) $56.8 \mu \mathrm{M}$ diphenhydramine, (6) $144.8 \mu \mathrm{M}$ levamisole, (7) $151.2 \mu \mathrm{M}$ lidocaine, (8) $182.5 \mu \mathrm{M}$ procaine, (9) $116.4 \mu \mathrm{M}$ prilocaine, (10) $516.5 \mu \mathrm{M}$ caffeine, (11) $143.3 \mu \mathrm{M}$ benzocaine, and (12) correspond to blank voltammogram. All voltammograms were recorded at $10 \mathrm{mV} / \mathrm{s}$ with the aqueous phase being $10 \mathrm{mM} \mathrm{HCl}(\mathrm{pH}=2)$. Voltammograms for caffeine and benzocaine are given after blank subtraction.

subjected to chemical analysis. These cutting agents include substances like sugars (glucose, maltose, lactose, etc.), boric acid, sodium bicarbonate, or nonillicit drugs among others. ${ }^{38}$ For the latter, the most frequently found cocaine street samples adulterating agents are caffeine, phenacetin, lidocaine, or paracetamol. ${ }^{38}$ Consequently, in this work, we focused our attention on electrochemical detection of cocaine and its frequently used cutting agents at the electrified liquid-liquid interface. With ion transfer voltammetry we investigated the effect of cocaine concentration, the $\mathrm{pH}$ of the aqueous phase, and the dimensions of the electroactive interface area on cocaine ion transfer behavior. Lastly, the validity of the proposed technique was confirmed on confiscated street samples.

\section{EXPERIMENTAL SECTION}

Chemicals. Potassium tetrakis(4-chlorophenyl)borate (KTPBCl, Sigma-Aldrich, 98\%) and bis(triphenylphosphoranylidene)ammonium chloride (BTPPACl, Sigma-Aldrich, 97\%) were used to prepare the organic phase electrolyte bis(triphenylphosphoranylidene)ammonium tetrakis(4-chlorophenyl)borate (BTPPATPBCl) via a simple metathesis reaction according to the protocol published elsewhere. $^{39}$ The organic phase was 1,2-dichloroethane (>99.5\%) from Sigma-Aldrich. The aqueous phase electrolyte was $10 \mathrm{mM} \mathrm{HCl}$ prepared using $1 \mathrm{M} \mathrm{HCl}$ volumetric solutions from Merck. Studied drugs: tetramethylammonium chloride (TMACl, 97\%), cocaine hydrochloride (analytical standard), procaine hydrochloride $(\geq 97 \%)$, acetylsalicylic acid $(\geq 99 \%)$, hydroxyzine dihydrochloride $(\geq 98 \%)$, levamisole hydrochlor- ide (analytical standard), diphenhydramine hydrochloride ( $\geq 98 \%$ ), lidocaine, benzocaine, phenacetin ( $\geq 98 \%)$, prilocaine hydrochloride $(\geq 98 \%)$, caffeine, diltiazem hydrochloride, boric acid $(99.9 \%)$, and glucose ( $>99.5 \%)$ were all from SigmaAldrich. Buffers were prepared using citric acid (>99\%) from VWR chemicals and sodium dihydrogen phosphate (>99\%) from Fluka. The $\mathrm{pH}$ of the aqueous phase was adjusted with 1 $\mathrm{M} \mathrm{NaOH}$ (volumetric solution from Fluka) or $1 \mathrm{M} \mathrm{HCl} . \mathrm{Ag} /$ $\mathrm{AgCl}$ reference electrodes were made via anodic silver oxidation in a $1 \mathrm{M} \mathrm{HCl}$ solution. Dissolution of gold wire was performed in the mixture of nitric acid $(>65.5 \%)$ and hydrochloric acid (37\%) at 3:1 (v:v) ratio, both from Sigma-Aldrich.

Electrochemical Experiments. Electrochemical measurements were performed using an Autolab PGSTAT302N or EmStat blue equipped with differential electrometer amplifier from PalmSens. The experiments at the macroITIES were performed in a classical four electrode electrochemical cell. ${ }^{40}$ Each phase contained one platinum counter electrode and one $\mathrm{Ag} / \mathrm{AgCl}$ reference electrode. The organic phase counter electrode was additionally covered with glass in order to prevent the contact with the aqueous phase. MicroITIES was prepared according to the protocol described in the Supporting Information. Briefly, the microwires having a diameter of $25 \mu \mathrm{m}$ were first sealed in a glass tube. Excess of glass was then removed by polishing, followed by wire dissolution in aqua regia. The remaining micropore was used to support the liquid-liquid interface. ${ }^{41}$ The electrochemical setup used to polarize microITIES consisted of a silver wire (being both the organic phase counter and the reference electrode) immersed directly into the organic phase present inside the capillary. ${ }^{42}$ Platinum electrode and $\mathrm{Ag} / \mathrm{AgCl}$ served as the counter and 
reference electrodes in the aqueous phase. Cell I and Cell II represent the composition of the electrochemical cells at the macro- and microITIES respectively:

Cell I.

$$
\begin{gathered}
\text { (aq)AglAgCl| }{ }_{10 \mathrm{mM} \mathrm{HCl}}^{x \mu \mathrm{drug}}\left|10 \mathrm{mMBTPPA}^{+} \mathrm{TPBCl}^{-}\right| \\
10 \mathrm{mM} \mathrm{BTPPA}^{+} \mathrm{Cl}^{-}|\mathrm{AgCl}| \mathrm{Ag}(\mathrm{org}) \\
10 \mathrm{mM} \mathrm{NaCl}
\end{gathered}
$$

Cell II.

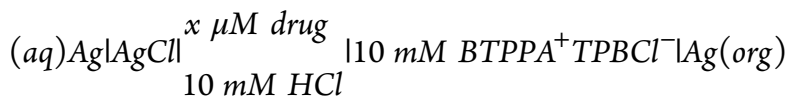

Wherever $\Delta_{\text {org }}^{\mathrm{aq}} \phi$ is used as a label of the $x$ axis of the recoded voltammograms, the potential of ion transfer is given as the standard Galvani potential difference calibrated using an internal reference $\mathrm{TMA}^{+}$with the $\Delta_{\mathrm{org}}^{\mathrm{aq}} \Phi_{\mathrm{TMA}}^{+0}=160 \mathrm{mV}^{43}$

Imaging. Scanning electron microscopy (SEM) images of the microcapillaries were acquired with a JEOL JSM 6010LA microscope. Optical images were acquired using a conventional optical microscope equipped with a CCD camera.

\section{RESULTS AND DISCUSSION}

At $\mathrm{pH}=2$, cocaine owning tertiary amine functionality with a $p K_{a}=8.70^{44}$ is protonated and, hence, positively charged. As deduced from the ion transfer voltammogram in Figure 1 cocaine undergoes reversible ion transfer reaction with the forward and reversed peak current intensities ratio $\approx 1$. Peak to peak separation $>59 / \mathrm{z} \mathrm{mV}$ is common at the electrified liquidliquid macrointerface and originates from the uncompensated resistance of the organic phase. ${ }^{45,46}$ The $\Delta_{\text {org }}^{a q} \Phi_{1 / 2}$ for cocaine equals $-76 \mathrm{mV}$ and suggests rather hydrophobic character of the molecule. Interfacial behavior of a number of cutting agents was investigated. Some of the commonly used adulterants like sugars, boric acid, and drugs with no ionizable or neutral (e.g., protonated carboxylic group) functionalities do not give a signal as shown in Figure S2. Drugs that were found to undergo electrochemically controlled interfacial ion transfer include diltiazem, hydroxyzine, diphenhydramine, levamisole, lidocaine, procaine, and prilocaine. For caffeine and benzocaine, ionic currents were overlaid with the background electrolyte ion transfer $\left(H_{a q \leftrightarrow o r g}^{+}\right)$and were located $>400 \mathrm{mV}$ toward more positive potential values as compared to the transfer potential of cocaine. Especially worth attention is lidocaine, being false positive in colorimetric Scott tests, ${ }^{47}$ with $\Delta_{\text {org }}^{a q} \Phi_{1 / 2}=115 \mathrm{mV}$ being far enough from the cocaine transfer potential.

The $\Delta_{\text {org }}^{a q} \Phi_{1 / 2}$ of levamisole $\left(\Delta_{\text {org }}^{a q} \Phi_{1 / 2}=7 \mathrm{mV}\right)$, procaine $\left(\Delta_{\text {org }}^{a q} \Phi_{1 / 2}=121 \mathrm{mV}\right)$, and prilocaine $\left(\Delta_{\text {org }}^{a q} \Phi_{1 / 2}=195 \mathrm{mV}\right)$ are also located on a more positive side of the potential window. Three drug molecules that give a signal at a potential similar to cocaine values are diltiazem $\left(\Delta_{\text {org }}^{a q} \Phi_{1 / 2}=-105 \mathrm{mV}\right)$, hydroxyzine $\left(\Delta_{\text {org }}^{a q} \Phi_{1 / 2}=-84 \mathrm{mV}\right)$, and diphenylhydramine $\left(\Delta_{\text {org }}^{a q} \Phi_{1 / 2}=-54 \mathrm{mV}\right)$. To further increase the voltammetric separation of the recorded signals, the partitioning of these drugs can be affected by replacing the organic solvent, offering a wider potential window (e.g., 1,2-dichlorobenzene, ${ }^{48}$ trifluorotoluene, ${ }^{49}$ or ionic liquids $\left.{ }^{50}\right)$. The interfacial potentials at which drug species are partitioning to the contacted phase can also be affected by acid-base equilibria. The change in the $\Delta_{\text {org }}^{a q} \Phi_{1 / 2}$ for cocaine recorded at different $\mathrm{pH}$ values (see Figure 2 and Figure S3 for ion transfer voltammograms) can be

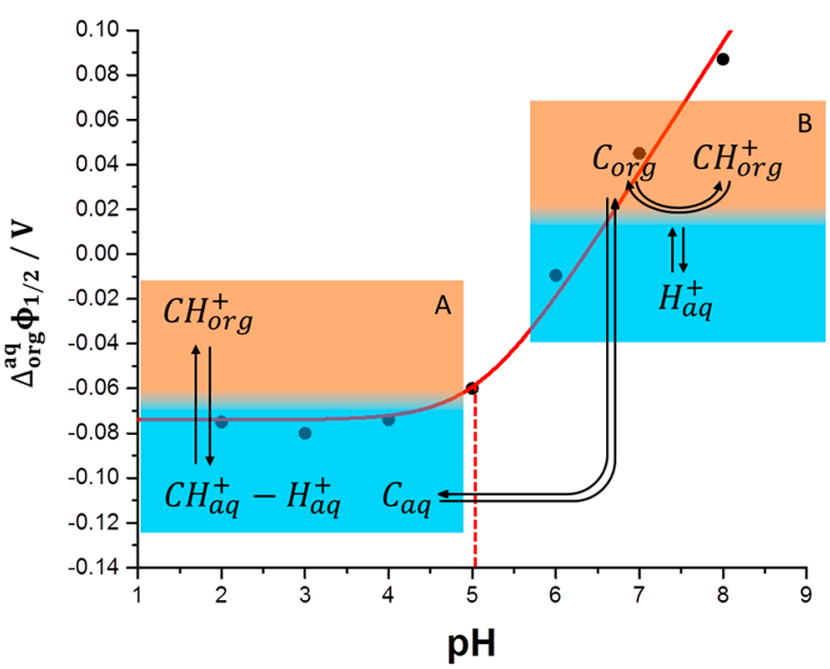

Figure 2. Ionic partition diagram for cocaine. Data points were measured experimentally. The red line corresponds to the theoretical model obtained using eq 1 . The dashed line corresponds to a $\mathrm{pH}$ where $\left[\mathrm{CH}_{a q}^{+}\right]=\left[\mathrm{C}_{\text {org }}\right]$. (A) Simple ion transfer reaction; (B) assisted ion transfer reaction.

explained assuming that both the protonated $\left(\mathrm{CH}^{+}\right)$and nonprotonated (C) cocaine species can partition across the liquid-liquid interface. Neglecting ion pair formation together with the assumption about the equality of cocaine diffusion coefficients in the aqueous and the organic phase, the $\mathrm{pH}$ dependent $\Delta_{\text {org }}^{a q} \Phi_{1 / 2}$ can be described using the following equation: ${ }^{51,52}$

$$
\Delta_{\text {org }}^{a q} \Phi_{1 / 2}=\Delta_{\text {org }}^{a q} \Phi^{\circ}+\frac{R T}{F} \ln \left(\frac{10^{-p H}+K_{a}+K_{a} K_{D}}{10^{-p H}}\right)
$$

where $\Delta_{o r g}^{a q} \Phi^{\circ}$ is the standard $\mathrm{CH}^{+}$ion transfer potential, $\mathrm{R}, T$, $F$, and $\mathrm{pH}$ have their usual meaning, $K_{a}$ is the acid dissociation constant for cocaine $\left(p K_{a}=8.70\right),{ }^{44}$ and $K_{D}$ is the distribution constant (also adjustable variable in eq 1 ) of the neutral form of cocaine $(\mathrm{C})$ between the aqueous and the organic phase:

$$
K_{D}=\frac{C_{C}^{a q}}{C_{C}^{o r g}}
$$

where $C_{C}^{a q}$ and $C_{C}^{\text {org }}$ are the concentrations of the neutral cocaine form in the aqueous and the organic phase, respectively. The best fit for the experimental values from Figure 2 was obtained for $K_{D} \approx 3.5$.

Direct information about the mechanism of the interfacial charge transfer reaction can be deduced from the ionic partition diagrams and voltammograms. ${ }^{53}$ At low $\mathrm{pH}$ values, and $\Delta_{\text {org }}^{a q} \Phi<$ $\Delta_{\text {org }}^{a q} \Phi^{\circ}$, the protonated $\mathrm{CH}_{a q}^{+}$form resides in the aqueous phase and can undergo simple ion transfer reaction when the $\Delta_{o r g}^{a q} \Phi$ is swept toward more positive values. At $\mathrm{pH}$ equal to around 5.1, the concentration of $\left[\mathrm{CH}_{a q}^{+}\right]=\left[\mathrm{C}_{\text {org }}\right]$, as deprotonated cocaine, can undergo spontaneous partitioning to the organic phase. The presence of the neutral form of cocaine in the organic phase facilitates the transfer of a proton from the aqueous phase which is recorded as the Faradaic current on the forward scan.

To further improve the electroanalytical performance of the ITIES based cocaine sensor, we performed miniaturization of the interface. This was achieved straightforwardly via a metal 

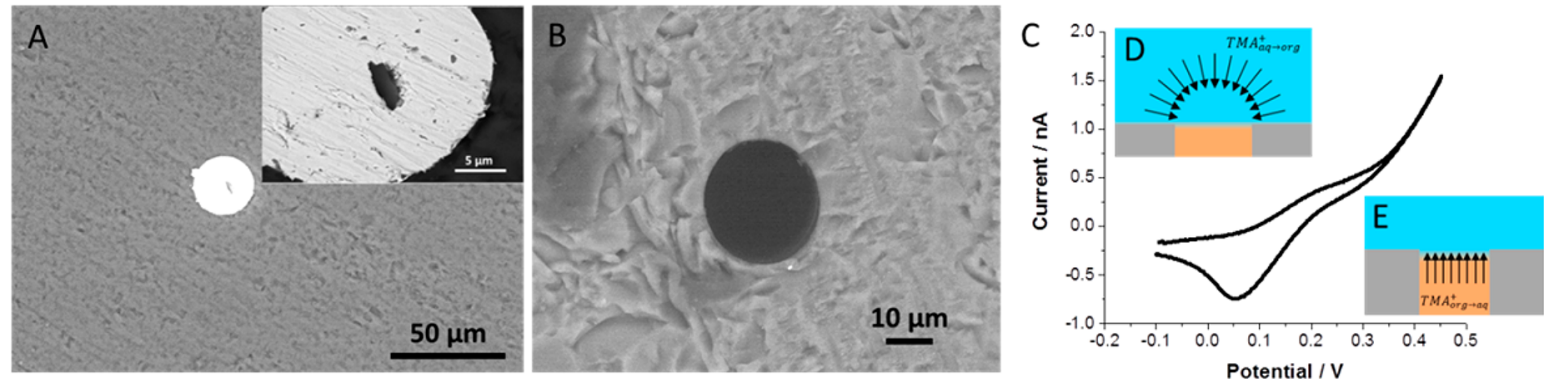

Figure 3. (A) SEM micrograph of a Au microelectrode in a glass sealing (inset shows the amplification of the region occupied by Au wire); (B) SEM micrograph of the hollow microcapillary after dissolution of the Au; (C) ion transfer voltammogram recorded for $\left[\mathrm{TMA}^{+}\right]=70.6 \mu \mathrm{M}$ at corresponding microITIES at $10 \mathrm{mV} / \mathrm{s}$. (D and E) Schemes of the hemispherical and linear diffusion regimes, respectively.

Table 1. Electroanalytical Characteristics of the Cocaine at Macro- and MicroITIES

$\begin{array}{lcccccc}\text { ITIES } & z & \mathrm{D}_{\text {literature, }} \mathrm{cm}^{2} \cdot \mathrm{s}^{-1} & D_{\text {experiment, }}{ }^{a} \mathrm{~cm}^{2} \cdot \mathrm{s}^{-1} & \mathrm{LOD}^{b} \mu \mathrm{M} & \mathrm{S},{ }^{c} \mathrm{~A} \cdot \mathrm{dm} \cdot \mathrm{mol}^{-1} & \Delta_{\text {org }}^{a q} \Phi^{\circ},{ }^{d} \mathrm{~V} \\ \text { Macro } & 1 & 2.7 \times 10^{-6} & 2.4 \times 10^{-6} & 30.1 & 5.3 & -72 \mathrm{mV} \\ \text { Micro } & & & & 10.9 & 549664.1\end{array}$

${ }^{a}$ Calculated based on Figure S4. ${ }^{b}$ Calculated according to $L O D=\frac{3.3 S_{d}}{S}$ where $S$ is the slope of the voltammetric calibration curve and $S_{d}$ is the standard error of its intercept. ${ }^{c} S$ is the slope of the calibration curve from Figure S5-C (macroITIES) and Figure S6-C (microITIES). ${ }^{d}$ Calculated according to ref 30 .

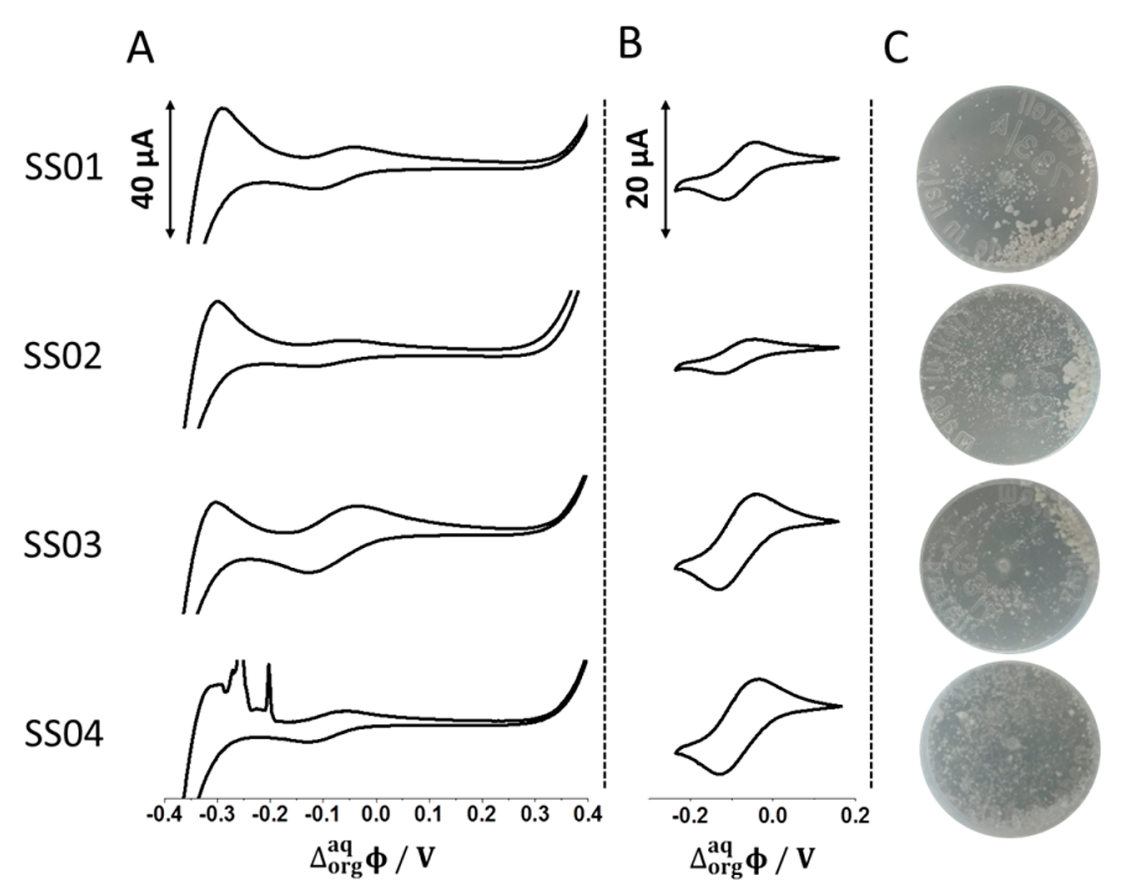

Figure 4. Four Street Samples (SS) investigated with cyclic voltammetry at the electrified liquid-liquid interface. Panel A corresponds to a full potential window. Panel B is the potential range where cocaine ion transfer is expected. Panel $\mathrm{C}$ is the picture of a street sample powder. Concentrations of street samples were: SS01-18.9 $\mu \mathrm{g} / \mathrm{mL}$; SS02-52.8 $\mu \mathrm{g} / \mathrm{mL}$; SS03-34.6 $\mu \mathrm{g} / \mathrm{mL}$; and SS04-27.2 $\mu \mathrm{g} / \mathrm{mL}$. All voltammograms were recorded at $10 \mathrm{mV} / \mathrm{s}$. The aqueous phase was $10 \mathrm{mM} \mathrm{HCl}$. Graphs and pictures in the rows correspond to the indicated street sample.

wire templated method. ${ }^{50,54}$ Figure $3 \mathrm{~A}$ shows the SEM micrograph of $25 \mu \mathrm{m}$ gold wire embedded in a glass insulator that was further dissolved in aqua regia to obtain a microhole, which is clearly visible in Figure 3B. The protocol of microcapillary preparation is described in the Supporting Information. Interfacial miniaturization brings a number of benefits: (i) ITIES supported within micro- or nanopores gains mechanical stability; (ii) the small dimensions of the system allow for very low chemicals consumption; (iii) miniaturization facilitates interface modification; ${ }^{42,33}$ (iv) small $i R$ drop permits the measurements in low conductivity media, (v) lower surface area decreases the capacitive current contribution, consequently lowering the limits of detection (LOD), ${ }^{55}$ and finally, (vi) the transfer of analyte toward the interface (in our case) from the aqueous side of the liquid-liquid interface is governed by nondiffiusion limited mass transfer only, which improves the overall sensitivity of a sensing platform. ${ }^{55}$ The microITIES prepared in our work has thick glass capillary walls meaning that pseudohemispherical diffusion regimes will be established on the aqueous side of the ITIES (see scheme in Figure 3D).

On the other hand, the mass transfer within the confined space of the capillary (Figure $3 \mathrm{E}$ ) is governed by the semi- 
infinitive linear-diffusion. ${ }^{56}$ Asymmetric properties of the microITIES are out-printed by unique voltammograms as shown in Figure $3 \mathrm{C}$, where the forward scan $\left(T M A_{a q \rightarrow o r g}^{+}\right)$is represented by a steady-state wave characteristic for the nondiffusion limited process and the backward scan $\left(T M A_{o r g}^{+} \rightarrow a q\right)$ gives a well-defined peak governed by diffusion limited mass transfer. The observed steady-state current can be described with ${ }^{56}$

$$
I_{s s}=4 D_{i} C_{i} F z r
$$

where $D_{i}$ is the aqueous phase diffusion coefficient of the transferring species, $C_{i}$ is the aqueous phase bulk concentration, $F$ is the Faraday constant, $z$ is the ionic charge, and $r$ is the radius of a microITIES. The steady-state current of a forward $T M A_{\text {aq } \rightarrow \text { org }}^{+}$transfer taken from Figure $3 \mathrm{C}, 0.46 \mathrm{nA}$, its diffusion coefficient equal to $13.8 \times 10^{-6} \mathrm{~cm}^{-2} \cdot \mathrm{s},{ }^{57}$ and corresponding $\left[\mathrm{TMA}^{+}\right]=70.6 \mu \mathrm{M}$ were substituted to eq 3 that gave ITIES diameter equal to $24.5 \mu \mathrm{m}$ (diameters measured with SEM oscilated from 24 to $26 \mu \mathrm{m}$ ). Such a simple scrutiny indicates that the liquid-liquid interface is formed on the pore ingress only and thin organic film formation on the bottom of the capillary can be excluded. Voltammetric detection of cocaine at the macro- and microITIES can be found in Figure S5 and Figure S6, respectively. Electroanalytical characteristics of cocaine at ITIES are summarized in Table 1 . The presented method allows for cocaine detection in a wide range of concentrations, starting from $20 \mu \mathrm{M}$ up to < hundreds of $\mathrm{mM}$. As expected we found that after miniaturization (i) the voltammetric sensitivity increased a few orders of magnitude and (ii) the calculated limit of detection (LOD) dropped from $30.1 \mu \mathrm{M}$ for macoITIES down to $10.9 \mu \mathrm{M}$ after interfacial downscaling. The obtained limits of detection are comparable with those reported for cocaine oxidation at nonmodified carbon based solid electrodes. ${ }^{58}$ LOD's from this work are also within concentration cutoff's of the colorimetric tests ${ }^{59}$ and at the same time offer significantly higher accuracy. The diffusion coefficient for the cocaine in the aqueous phase was found to be $2.4 \times 10^{-6} \mathrm{~cm}^{2} \mathrm{~s}^{-1}$, which agrees well with the value reported elsewhere $2.7 \times 10^{-6} \mathrm{~cm}^{2} \mathrm{~s}^{-1}$. 60

To confirm the validity of our method we have randomly chosen four street samples (SS) and analyzed them at the macroITIES as shown in Figure 4. Prior to the analysis, each SS was dissolved in $10 \mathrm{mM} \mathrm{HCl}$ being aqueous phase. Out of four samples investigated only SS04 dissolved entirely. Samples SS01-SS03 were only partially soluble despite sonication. For each SS the pair of two peaks with $\Delta_{\text {org }}^{a q} \Phi_{1 / 2}=-76 \mathrm{mV}$ was detected indicating the presence of cocaine. For SS04 some irregular spikes around $-150 \mathrm{mV}$ were observed indicating the presence of surface active species (presumably in the aqueous phase) leading to a phenomenon known as electrochemical instability. ${ }^{61}$ Based on the height of the voltammetric signal and the calibration curve from Figure S5B, the purity of each sample was estimated to be SS01, 70\%; SS02, 8\%; SS03, 82\%; and SS04, 98\%. When it comes to real applications, the practical limitations of the electrochemical cells (glass four electrode cell or micropore-capillaries) used in this work can be overcome with the screen printing technology and miniaturization. ${ }^{62}$ Another recognized practical limitation pertains to the volatility of the organic phase, which can be solved by the formation of a so-called organo-gel phase ${ }^{63}$ or by simple replacement with nontoxic hydrophobic ionic liquids. ${ }^{41}$

\section{CONCLUSIONS}

The proposed method shows how ITIES can be used to detect cocaine, even from complex mixtures such as cocaine street samples. The selectivity of the system is purely based on molecular partitioning being governed by the molecular structure. Most of the investigated cutting agents were electrochemically inactive or gave a signal at potentials distinct from the potential of cocaine ion transfer. Electroanalytical detection of cocaine was performed at macro- and microITIES. For both systems, detection spans from $\mu \mathrm{M}$ to $\mathrm{mM}$ with the limits of detection approaching a few $\mu \mathrm{M}$. Further improvement in cocaine sensing with the help of ITIES is envisaged.

\section{ASSOCIATED CONTENT}

\section{Supporting Information}

The Supporting Information is available free of charge on the ACS Publications website at DOI: 10.1021/acs.analchem.8b00916.

Additional information concerning microITIES preparation; ion transfer voltammograms for interfacially inactive cutting agents; ion transfer voltammograms for cocaine ion transfer at different $\mathrm{pH}$ values, and calibration curves for cocaine recorded at macro- and microITIES. (PDF)

\section{AUTHOR INFORMATION}

\section{Corresponding Author}

*E-mail: 1.poltorak@tudelft.nl.

ORCID

Lukasz Poltorak: 0000-0002-8799-8461

Ernst J. R. Sudhölter: 0000-0003-3296-953X

Notes

The authors declare no competing financial interest.

\section{ACKNOWLEDGMENTS}

All authors are grateful to Duco Bosma for technical support. LP is grateful to the department of Chemical Engineering (TU Delft) for his postdoctoral scholarship.

\section{REFERENCES}

(1) European Monitoring Centre for Drugs and Drug Addiction. The state of the drugs problem in Europe; 2010.

(2) United Nations Office on Drugs and Crime. World drug report; 2016.

(3) UNODC. Market analysis of plant-based drugs - opiates, cocaine, cannabis; 2017.

(4) Tsumura, Y.; Mitome, T.; Kimoto, S. Forensic Sci. Int. 2005, 155 $(2-3), 158$.

(5) Mokhtarzadeh, A.; Ezzati Nazhad Dolatabadi, J.; Abnous, K.; de la Guardia, M.; Ramezani, M. Biosens. Bioelectron. 2015, 68, 95.

(6) Xie, S. J.; Zhou, H.; Liu, D.; Shen, G. L.; Yu, R.; Wu, Z. S. Biosens. Bioelectron. 2013, 44 (1), 95-100.

(7) Shi, Y.; Dai, H.; Sun, Y.; Hu, J.; Ni, P.; Li, Z. Analyst 2013, 138 (23), 7152.

(8) Stojanovic, M. N.; de Prada, P.; Landry, D. W. J. Am. Chem. Soc. 2001, 123 (21), 4928.

(9) Zhang, J.; Wang, L.; Pan, D.; Song, S.; Boey, F. Y. C.; Zhang, H.; Fan, C. Small 2008, 4 (8), 1196.

(10) Liu, J.; Lu, Y. Angew. Chem. 2006, 118 (1), 96.

(11) Stojanovic, M. N.; Landry, D. W. J. Am. Chem. Soc. 2002, 124 (33), 9678

(12) Neves, M. a. D.; Blaszykowski, C.; Thompson, M. Anal. Chem. 2016, 88 (6), 3098. 
(13) Neves, M. a D.; Blaszykowski, C.; Bokhari, S.; Thompson, M. Biosens. Bioelectron. 2015, 72, 383.

(14) Kawano, R.; Osaki, T.; Sasaki, H.; Takinoue, M.; Yoshizawa, S.; Takeuchi, S. J. Am. Chem. Soc. 2011, 133 (22), 8474.

(15) Rauf, S.; Zhang, L.; Ali, A.; Liu, Y.; Li, J. ACS Sensors 2017, 2 (2), 227.

(16) Zhang, D. W.; Zhang, F. T.; Cui, Y. R.; Deng, Q. P.; Krause, S.; Zhou, Y. L.; Zhang, X. X. Talanta 2012, 92, 65.

(17) Beigloo, F.; Noori, A.; Mehrgardi, M. a.; Mousavi, M. F. J. J. Iran. Chem. Soc. 2016, 13 (4), 659.

(18) Roushani, M.; Shahdost-Fard, F. Anal. Chim. Acta 2015, 853 (1), 214.

(19) Swensen, J. S.; Xiao, Y.; Ferguson, B. S.; Lubin, A. a.; Lai, R. Y.; Heeger, A. J.; Plaxco, K. W.; Soh, H. T. J. Am. Chem. Soc. 2009, 131 (12), 4262.

(20) Baker, B. R.; Lai, R. Y.; Wood, M. S.; Doctor, E. H.; Heeger, A. J.; Plaxco, K. W. J. Am. Chem. Soc. 2006, 128 (10), 3138.

(21) Zuo, X.; Xiao, Y.; Plaxco, K. W. J. Am. Chem. Soc. 2009, 131, 6944.

(22) Wen, Y.; Pei, H.; Wan, Y.; Su, Y.; Huang, Q.; Song, S.; Fan, C. Anal. Chem. 2011, 83 (19), 7418.

(23) Jiang, B.; Wang, M.; Chen, Y.; Xie, J.; Xiang, Y. Biosens. Bioelectron. 2012, 32 (1), 305.

(24) Asturias-Arribas, L.; Alonso-Lomillo, M. A.; DomínguezRenedo, O.; Arcos-Martínez, M. J. Anal. Chim. Acta 2014, 834 (1), 30.

(25) Freitas, J. M.; Ramos, D. L. O.; Sousa, R. M. F.; Paixão, T. R. L. C.; Santana, M. H. P.; Muñoz, R. a. a.; Richter, E. M. Sens. Actuators, B 2017, 243, 557.

(26) De Jong, M.; Sleegers, N.; Kim, J.; Van Durme, F.; Samyn, N.; Wang, J.; De Wael, K. Chem. Sci. 2016, 7 (3), 2364.

(27) Reymond, F.; Lee, H. J.; Girault, H. H.; Fermin, D. Electrochim. Acta 2000, 45 (15-16), 2647.

(28) Kontturi, K.; Murtomäki, L. J. Pharm. Sci. 1992, 81 (10), 970.

(29) Bouchard, G.; Carrupt, P. A.; Testa, B.; Gobry, V.; Girault, H. H. Pharm. Res. 2001, 18 (5), 702.

(30) Poltorak, L.; Sudhölter, E. J. R.; de Smet, L. C. P. M. J. Electroanal. Chem. 2017, 796 (April), 66.

(31) Yuan, Y.; Amemiya, S. Anal. Chem. 2004, 76 (23), 6877.

(32) Arrigan, D. W. M.; Ghita, M.; Beni, V. Chem. Commun. (Cambridge, U. K.) 2004, 6, 732.

(33) Poltorak, L.; Morakchi, K.; Herzog, G.; Walcarius, A. Electrochim. Acta 2015, 179, 9.

(34) Hu, D.; Wang, H.; Gao, K.; Jiang, X.; Wang, M.; Long, Y.; Chen, Y. RSC Adv. 2014, 4 (100), 57035.

(35) Iwai, N. T.; Kramaric, M.; Crabbe, D.; Wei, Y.; Chen, R.; Shen, M. Anal. Chem. 2018, 90, 3067.

(36) Gulaboski, R.; Cordeiro, M. N. D. S.; Milhazes, N.; Garrido, J.; Borges, F.; Jorge, M.; Pereira, C. M.; Bogeski, I.; Morales, A. H.; Naumoski, B.; Silva, a. F. Anal. Biochem. 2007, 361 (2), 236.

(37) Wägli, P.; Chang, Y. C.; Homsy, A.; Hvozdara, L.; Herzig, H. P.; De Rooij, N. F. Anal. Chem. 2013, 85 (15), 7558.

(38) Broséus, J.; Gentile, N.; Esseiva, P. Forensic Sci. Int. 2016, 262, 73.

(39) Chopineaux-Courtois, V.; Reymond, F.; Bouchard, G.; Carrupt,

P. A.; Testa, B.; Girault, H. H. J. Am. Chem. Soc. 1999, 121 (8), 1743.

(40) Méndez, M. a.; Partovi-Nia, R.; Hatay, I.; Su, B.; Ge, P.; Olaya, A.; Younan, N.; Hojeij, M.; Girault, H. H. Phys. Chem. Chem. Phys. 2010, 12 (46), 15163.

(41) Stockmann, T. J.; Ding, Z. J. Phys. Chem. B 2012, 116, 12826.

(42) Poltorak, L.; Herzog, G. G.; Walcarius, A. Langmuir 2014, 30

(38), 11453.

(43) Wandlowski, T.; Merecek, V.; Samec, Z.; Mareček, V.; Samec, Z. Electrochim. Acta 1990, 35 (7), 1173.

(44) Luan, F.; Ma, W.; Zhang, H.; Zhang, X.; Liu, M.; Hu, Z.; Fan, B. Pharm. Res. 2005, 22 (9), 1454.

(45) Su, B.; Abid, J.-P.; Fermín, D. J.; Girault, H. H.; Hoffmannová, H.; Krtil, P.; Samec, Z. J. Am. Chem. Soc. 2004, 126 (3), 915.

(46) Kakiuchi, T.; Tsujioka, N. Electrochem. Commun. 2003, 5 (3), 253.
(47) Haddoub, R.; Ferry, D.; Marsal, P.; Siri, O. New J. Chem. 2011, 35 (7), 1351.

(48) Peljo, P.; Murtomäki, L.; Kallio, T.; Xu, H. J.; Meyer, M.; Gros, C. P.; Barbe, J. M.; Girault, H. H.; Laasonen, K.; Kontturi, K. J. Am. Chem. Soc. 2012, 134 (13), 5974.

(49) Olaya, A. J.; Ge, P.; Girault, H. H. Electrochem. Commun. 2012, 19, 101.

(50) Stockmann, T. J.; Ding, Z. J. Electroanal. Chem. 2010, 649 (12), 23.

(51) Nakamura, M.; Osakai, T. J. Electroanal. Chem. 2016, 779, 55.

(52) Osakai, T.; Yamada, H.; Nagatani, H.; Sagara, T. J. Phys. Chem. C 2007, 111 (26), 9480.

(53) Reymond, F.; Steyaert, G.; Carrupt, P. A.; Testa, B.; Girault, H. J. Am. Chem. Soc. 1996, 118 (47), 11951.

(54) Cunnane, V. J.; Schiffrin, D. J.; Williams, D. E. Electrochim. Acta 1995, 40 (18), 2943.

(55) Scanlon, M. D.; Arrigan, D. W. M. Electroanalysis 2011, 23 (4), 1023.

(56) Liu, S.; Li, Q.; Shao, Y. Chem. Soc. Rev. 2011, 40 (5), 2236.

(57) Hinoue, T.; Ikeda, E.; Watariguchi, S.; Kibune, Y. Anal. Chem. 2007, 79 (1), 291.

(58) De Jong, M.; Sleegers, N.; Kim, J.; Van Durme, F.; Samyn, N.; Wang, J.; De Wael, K. Chem. Sci. 2016, 00, 1.

(59) Fastect II Drug Screen Test, https://www.alcopro.com/ product/fastect-ii-cocaine/ (accessed Mar 16, 2018).

(60) Abedul, M. T. F.; Rodríguez, J. R. B.; García, A. C.; Blanco, P. T. Electroanalysis 1991, 3 (4-5), 409.

(61) Kasahara, T.; Nishi, N.; Yamamoto, M.; Kakiuchi, T. Langmuir 2004, 20 (3), 875.

(62) Lee, H. J.; Lagger, G.; Pereira, C. M.; Silva, A. F.; Girault, H. H. Talanta 2009, 78 (1), 66.

(63) Sairi, M.; Arrigan, D. W. M. Talanta 2015, 132, 205. 